\title{
Geomagnetic Reversals:
}

\section{Rates, Timescales, Preferred Paths,}

Statistical Models and Simulations

\author{
Catherine Constable \\ Institute of Geophysics and Planetary Physics \\ Scripps Institution of Oceanography \\ University of California at San Diego \\ La Jolla, Ca 92093-0225, USA. \\ cconstable@ucsd.edu
}

\author{
Chapter 4 \\ Earth's Core and Lower Mantle \\ Volume Editors \\ Christopher A. Jones, Andrew M. Soward and Keke Zhang \\ in \\ The Fluid Mechanics of Astrophysics and Geophysics \\ (Series Editors, Andrew Soward and Michael Ghil)
}

Keywords: Geomagnetic reversals, Reversal rates, Paleointensity, Statistics of Geodynamo 


\begin{abstract}
Paleomagnetic data on geomagnetic reversals are divided into two general categories: times of occurrence, and records of directional and/or intensity changes for transitions at individual locations. Despite considerable efforts expended in acquiring paleomagnetic reversal records, a detailed picture of the reversal process is still lacking, along with any means of clearly identifying when the magnetic field has entered a transitional state destined to lead to a reversal. Accurate dating remains critical to making inferences about timing and structure of reversals and excursions. Controversy remains about the significance of such features as the preferred longitudinal paths that virtual geomagnetic poles at some sites seem to follow during excursions and reversals. Reversal rates are estimated under the assumption that reversal occurrence times can be described as a Poisson process. Correlations are sought between reversal rates and other properties of the paleomagnetic secular variation, and more general models for reversals and secular variations are being developed to provide predictions of the power spectrum of geomagnetic intensity variations for comparison with those derived from long paleomagnetic records. These analyses may ultimately allow the identification of any characteristic time scales associated with the geomagnetic reversal process, and should prove useful in evaluating the behavior observed from numerical simulations of the geodynamo.
\end{abstract}

\title{
1. Introduction
}

In the early 1900's study of the magnetization of rocks in France and Italy led Bernard Brunhes to conclude that Earth's magnetic field had formerly had the opposite direction to that observed today. The evidence for geomagnetic reversals was not, however, generally accepted as conclusive until the 1960's, by which time compelling evidence of global reversals was assembled for radiometrically dated rocks (Cox et al., 1964). At about the same time Vine and Matthews (1963) interpreted the magnetic anomaly record from the Indian Ocean as the record in seafloor rocks of the reversing geomagnetic field. While it is plausible that the magnetic field has been reversing throughout most of its existence, the recovery of magnetostratigraphic records becomes increasingly challenging as the time scale is extended beyond the age of the seafloor. Prior to $2 \mathrm{Ga}$ there is at present no record of a succession of several magnetic reversals, while between 2 and $1 \mathrm{Ga}$ such records are rare (Pavlov \& Gallet, 2001), and difficulties in obtaining precise dating constraints mean that even estimating the reversal rate is a far from straightforward task. Although the rate at which reversals occur is not uniformly well-determined, it is nevertheless clear that the rate has varied throughout geological time and, perhaps more surprisingly, there exist a few long time intervals, when there have been very few or no reversals, the most recent example being the almost $40 \mathrm{Myr}$ period known as the Cretaceous Normal Superchron, which ended at about 83 Ma.

Geomagnetic records in volcanic rocks and seafloor magnetic anomalies remain critically important in geomagnetic reversal studies today, although the emphasis has now shifted from establishing the global validity of geomagnetic reversals to understanding their detailed structure and origin and what this may reveal about the geodynamo (e.g., Jacobs, 1994; Merrill et al., 1996). Sedimentary rocks can also preserve a record of the reversing geomagnetic field, although the timing of remanence acquisition and/or the possible smoothing of the geomagnetic record requires careful evaluation (e.g., Langereis et al., 1992; Tauxe et al., 1996; Clement, 2000). Typically the paelomagnetic record preserved in volcanic and sedimentary rocks is used to study the details of directional and (where possible) intensity changes for transitions at individual locations, while the oceanic magnetic anomaly records provide the times of occurrence for reversals and thus reversal rate, although increasingly the marine record is being interpreted in more detail as attempts are made to separate the effects of paleointensity fluctuations from those attributable to variable mineral magnetism in the magnetic anomaly record (see for example, Kent \& Carlut, 2000; Gee et al., 2000; Pouliquen et al., 2001).

Geomagnetic reversals remain a fascinating but rather poorly understood phenomenon, in part because of the fragmentary and inherently inaccurate nature of the geological record. From paleomagnetic records it is known that the intensity of the magnetic field decreases drastically during reversals, that the field structure is non-zonal, and reversals take of the order of thousands of years. However, despite several decades of reversal studies, the existence of consistent field structures during reversals is debated, and the characteristic timescales remain poorly defined. Also despite considerable advances in numerical simulations of the dynamics of geomagnetic field behavior, such numerical models cannot be operated in the parameter 
regime considered appropriate for Earth, and therefore only provide general guidelines about the behavior to be expected for self-sustaining dynamos. This chapter is concerned with the paleomagnetic record of geomagnetic reversals and its interpretation in the light of both phenomenological models for geomagnetic reversals and the increasingly prevalent numerical models of the geodynamo. We first attempt some working definitions of geomagnetic reversals, and their relation to excursions and what is sometimes called normal secular variation. We consider the time scales involved in reversal processes, including changes in reversal rates, how the time scales are measured and the current limitations on such measurements. Knowledge of the time scales involved is critical to the resolution of such controversial issues as whether the geomagnetic pole follows a prefered path or paths during reversal, or preferentially occupies particular geographic locations for extended periods of time.

We conclude with a look towards what may or may not be resolved in the near future by reversal studies, and the prospects on how they may inform us on the workings of the geodynamo.

\section{Working Definitions for Reversals and Excursions}

When it is not in a transitional state the geomagnetic field can be represented to first order by that of a geocentric dipole. This representation has become an entrenched part of paleomagnetic analyses (even when the field is reversing), so that it is common for measurements of the magnetic field to be expressed in terms of virtual geomagnetic pole (VGP) positions and virtual dipole moments (VDMs). A VGP gives the geographic coordinates on Earth's surface of the North Polar axis of the geocentric dipole that would generate the observed local field direction, and effectively removes the gross geographic variations attributable to a field of dipolar origin. We think of the VGP as a unit vector $\hat{v}$, associated with a vector dipole moment $\vec{V}$ in a geocentric coordinate system associated with a local field vector $\vec{B}$ at a site location at $\vec{s}$. Although the VGP transformation is conventionally given in terms of spherical trigonometry (e.g., Merrill et al., 1996) it is in fact a linear transformation on $\vec{B}$ as indicated by Egbert (1992): that is we can write

$$
\vec{V}(\vec{s})=R(s, \theta, \phi) \vec{B}(\vec{s})
$$

with $R$ at a location with radius $s$, colatitude $\theta$, and longitude $\phi$ given explicitly by

$$
R(s, \theta, \phi)=\frac{4 \pi s^{3}}{\mu_{0}}\left(\begin{array}{ccc}
-\cos \theta \cos \phi & \sin \phi & \frac{1}{2} \sin \theta \cos \phi \\
-\cos \theta \sin \phi & -\cos \phi & \frac{1}{2} \sin \theta \sin \phi \\
\sin \theta & 0 & \frac{1}{2} \cos \theta
\end{array}\right)
$$

while a VDM is the magnetic moment $|V|$ that a geocentric dipole would have in order to generate the observed field intensity. Thus

$$
V=|\vec{V}| \quad \hat{v}=\frac{\vec{V}}{|\vec{V}|}
$$

Although $\hat{v}$ can be derived from directional measurements alone, $V$ requires knowledge of the magnetic inclination in addition to field magnitude. A variant on these transformations is the virtual axial dipole moment (VADM) which is the dipole moment corresponding to a geocentric dipole aligned with the geographic axis. Although VGPs and VDMs are widely thought of as representations that approximate the geomagnetic field as a dipole it can be seen from the above that they are simply linear transformations of the local magnetic field vector, and still contain all the nondipole contributions to the magnetic field. They can thus be used to describe any geomagnetic field structure whether or not it is predominantly dipolar, but the interpretation of the non-dipolar field contributions is less obvious than for a dominantly dipolar field. Figure 1(a) shows the concentration distribution of VGPs, derived from a uniform sampling of the geomagnetic field in 2000 (predicted from Ørsted initial field model (OIFM) of Olsen et al., 2000). The VGPs are most concentrated about the geomagnetic dipole axis reflecting the predominantly dipolar structure, however, there are occasional outliers up to 30 or $40^{\circ}$ from the dipole axis, reflecting the second and higher order structure of the field. A purely dipolar field would have all the VGPs concentrated at a single point corresponding to the dipole axis. During a reversal the axial dipole part of the field is expected to be greatly diminished for a prolonged 


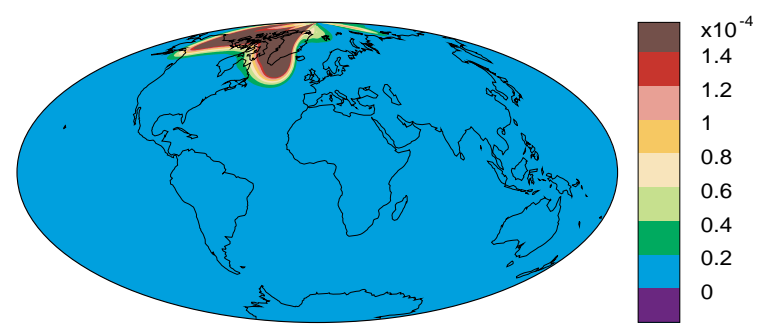

(a) OIFM 2000

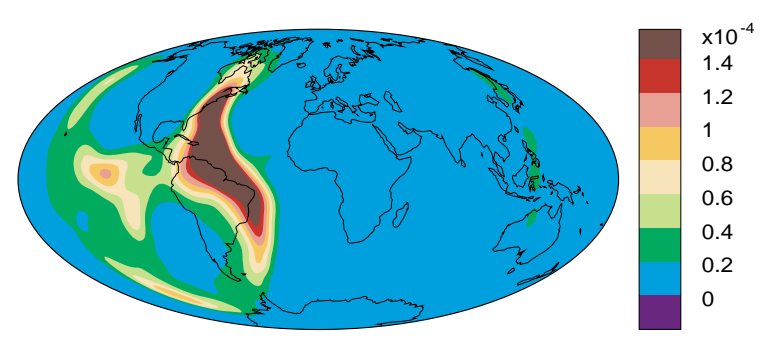

(b) OIFM 2000 No Axial Dipole

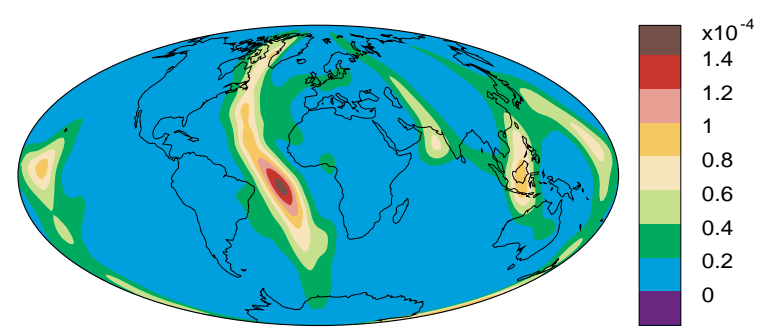

(c)OIFM 2000 No dipole

Figure 1: Probability density of VGP positions for OIFM 2000 (a) includes $g_{1}^{0}$, (b) omitting $g_{1}^{0}$ (c) omitting all dipole terms.

time interval and must certainly vanish at some point. In Figure 1(b) the axial dipole part of the field is removed from OIFM revealing a field that may be similar in some ways to what might be expected during a reversal, and the second order structure exhibits a different latitudinal distribution for $\hat{v}$ : there are particularly heavy concentrations just east of the Americas, and subsidiary concentrations in parts of the Pacific and in a longitudinal band extending from Eastern Asia down through Western Australia. These concentrations arise from the higher order structure in the field. The origin of these concentrations can be seen in Figure 2 (a) where the actual latitudes for each VGP from OIFM are contoured for geographic locations. From this we can see which locations contribute the VGPs with greatest departures from the geographic axis: in (a) the lowest VGP latitudes for OIFM occur in the southern Indian Ocean and around Antarctica. The picture appears quite different when the axial-dipole part of the field is removed in (b), exposing VGP latitudes less than zero over large regions in both the northern and southern hemisphere. Figures 3 (a) and (b) show the values of VGP longitudes as a function of geographic location: they are identical because $g_{1}^{0}$, the axial dipole field contribution has no longitude dependence. The difficulty in rapidly comprehending the structure of the geomagnetic field from concentrations of $\hat{v}$ or its location for individual sites can be readily appreciated from the differences between Figures 1-3 parts (b) and (c). In part (c) of each figure the entire dipole contribution, as oppose to just the axial dipole in (b), has been removed from OIFM: it is seen that $\hat{v}$ and its statistical distribution can look quite different depending on the form of the equatorial dipole terms once the axial dipole is removed or much reduced in magnitude. Since the equatorial dipole terms are known to change on relatively short time scales (e.g., Constable et al., 2000), and their overall contributions to the dipole field 


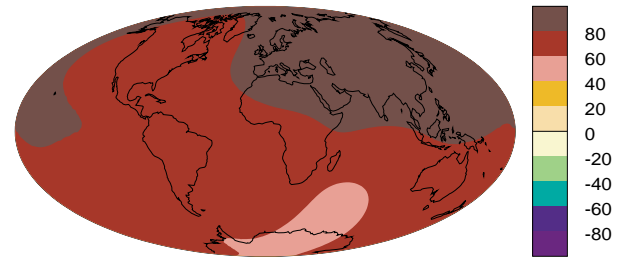

(a) OIFM 2000 VGP Latitude

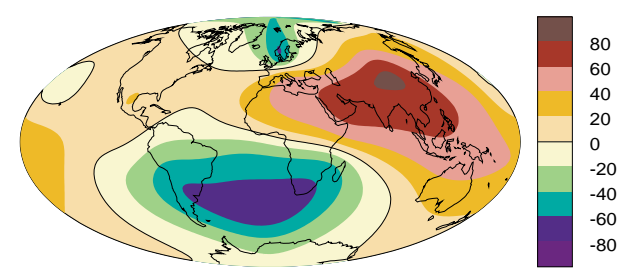

(b) OIFM 2000 VGP Latitude, No Axial Dipole

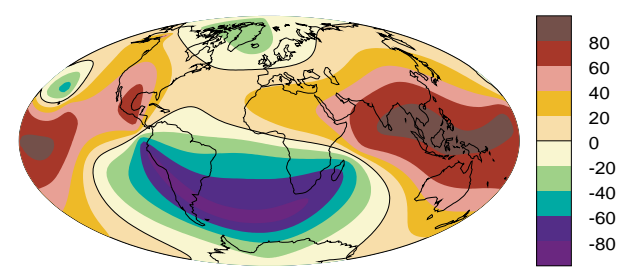

(c) OIFM 2000 VGP Latitude, No Dipole

Figure 2: Predicted VGP Latitudes from OIFM 2000

(a) including $g_{1}^{0}$, (b) omitting $g_{1}^{0}$, (c) omitting all dipole terms

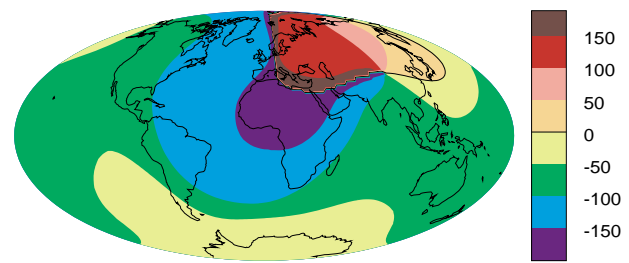

OIFM 2000 VGP Longitude

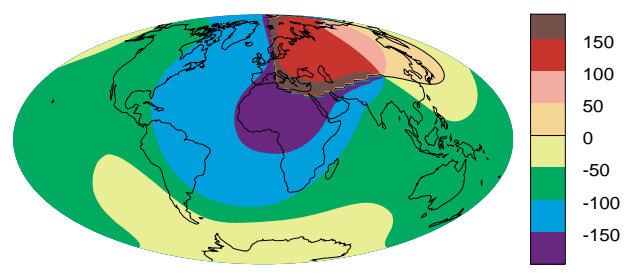

OIFM 2000 VGP Longitude, No Axial Dipole

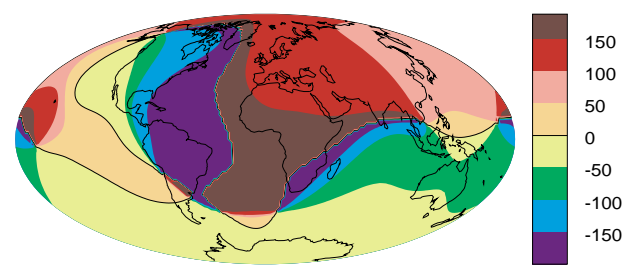

OIFM 2000 VGP Longitude, No Dipole

Figure 3: Same as Figure 2, but for VGP longitude. Note that the VGP longitudes are the same whether or not the axial dipole term is included, because it has no dependence on longitude.

may be quite small, there might be good reasons for considering Figure 1-3(c) as at least as likely to be representative of what goes on during a reversal as Figures 1-3(b).

A time interval in which the geomagnetic field is predominantly of one polarity is known as a chron: typical lengths range from of the order of $0.1-1 \mathrm{Myr}$, with those rare extremely long intervals dominated by one polarity being designated superchrons. Short intervals of stable polarity $\sim 10-100 \mathrm{kyr}$ are called subchrons. Transitional geomagnetic field directions are often defined in terms of a minimum angular departure of $\hat{v}$ from the rotation axis: the numerical value typical ranges from about $40-50^{\circ}$, and reflects the perception that the average dispersion about this axis during stable polarity times ranges from about $12^{\circ}$ at the equator to somewhere around $20^{\circ}$ near the pole (e.g., McFadden et al., 1991). The root mean square value of this angular deviation of $\hat{v}$ from the rotation axis is widely interpreted as a measure of the variability in the geomagnetic field due to secular variation for non-transitional magnetic field states. Merrill et al. (1996) define a geomagnetic reversal as a "globally observed $180^{\circ}$ change in the dipole field averaged over a few thousand years". The generality of this definition arises from the genuine difficulty in identifying from paleomagnetic records the time at which the field is irrevocably committed to reversing rather than returning to its starting polarity: it appears that only after the fact can one be sure that a geomagnetic reversal has taken place. Brief excursions of the geomagnetic field have been documented in which at some locality the VGP position is observed to deviate more than some threshold amount from the geographic axis (e.g., Verosub, 1977 specified an angular deviation of $>45^{\circ}$ ), and then return to the original polarity rather than executing a full reversal. Such excursions are usually accompanied by decreases in the local geomagnetic field intensity. Some of these excursions are documented in a number of locations with sufficient precision in age that they are taken to be contemporaneous (e.g., the Laschamp excursion occurring at about $40 \mathrm{ka}$, Chauvin et al., 1989; Levi et al., 1990; Thouveny et al., 1992; Vlag et al.,1996; Nowaczyk et al., 1997). A widespread interpretation of excursions is as aborted reversals in which the field returns to its original state after a large perturbation. Observationally, excursions are distinguished from subchrons by the fact that the 
field does not apppear to achieve a fully-reversed stable state. Features which could be thought of in the same category as excursions are the cryptochrons, events observed in magnetic anomaly data that typically last less than 30kyr (Cande \& Kent, 1992): although the resolution of the magnetic anomaly record is only rarely sufficient to distinguish whether these correspond to subchrons, excursions, or geomagnetic intensity fluctuations.

Recent articles on dating short geomagnetic field events during the current polarity interval find 10 or more excursions of the geomagnetic field (Langereis et al., 1997; Lund et al., 1998) during the Brunhes chron. In comparison with the last reversal which occurred at $0.78 \mathrm{Ma}$ these are rather poorly documented, with at most a handful of sites recording any individual event. In contrast Love \& Mazaud (1997) in constructing a database of records of the last reversal derived from sedimentary rocks or lava flows uncovered 62 distinct records of the Matuyama-Brunhes transition, although after applying their selection criteria concerning number of time samples and lab analyses they were only able to retain 11 of these for more detailed analyses of field structure. In the time interval 0-158 Ma there are about 295 reversals in the marine magnetic anomaly record plus another 112 events identified as cryptochrons (Cande \& Kent 1992; Harland et al. 1990; Constable, 2000). Because of the uneven temporal resolution in the record more short events may be identified in the future. For the vast majority of known reversals no detailed geological record has yet been uncovered.

Figure 1 shows that in terms of individual site records using departures of say $45^{\circ}$ or more of VGPs from the geographic axis as the criterion for identifying excursional observations is inadequate. Although the present field is stable by this criterion (Fig 1(a)), with the axial dipole contribution to the present field removed as in (b) there are places with VGP latitudes close to $90^{\circ}$, which by a casual interpretation would not appear to be taking part in any excursional activity, despite the absence of a dominant axial dipole. The same hold true, although to a lesser degree, in (c). Yet by any reasonable criterion the fields in both (b) and (c) would be considered anomalous when compared with the present field.

A plausible interpretation of what can be found in the paleomagnetic record is that the geomagnetic field exhibits a continuum of behavior in its secular variation so that in fact there is no clearly defined excursional state, but occasional large departures from the average state which may or may not ultimately result in a reversal. This idea ties in quite well with other views about the importance of the inner core in stabilizing numerical and by inference real dynamos to produce more Earth-like behavior (Hollerbach and Jones, 1993a,b; 1995; Clement and Stixrude, 1995; Gilder and Glen, 1998). It is also consistent with an absence of identifiable triggers or other signature features for the reversals that are seen in numerical simulations of geodynamos (e.g.. Coe et al. , 2000; McMillan et al. 2001). Gubbins (1999) has suggested that a possible distinction between excursions and reversals may be that during excursions the field may reverse in the liquid outer core, which has typical timsecales of 500 years or less, but not in the solid inner core where the relevant diffusion time scale is several thousand years. In order for a reversal to be carried through to completion the reverse polarity must diffuse into the inner core. One possible implication is that reversals and excursions could have different characteristic time scales in the associated magnetic field changes. This highlights the importance of being able to determine the age and duration of geomagnetic events of all types, a topic to be discussed in the next section.

\section{Dating and Time Scales}

Dating for paleomagnetic records, and the geomagnetic information that comes with it, comes from a number of sources with assorted levels of accuracy and resolution and corresponding to applications in studying particular geomagnetic phenomena. The crudest form of geomagnetic information (the polarity of the field) comes in the form of the global magnetostratigraphic time scale, which supplies a time at which the geomagnetic field reversed, with the associated implication that at this level of resolution it can be considered instantaneous. The absolute timing of the magnetic anomalies is linked to age provided for specific isotopic tie points in the scale (see for example Cande \& Kent, 1995). The accuracy of the time scale depends on the accuracy of the tie points and the validity of the assumptions concerning constancy of seafloor spreading rate between tie points. The resolution provided by picking anomalies ranges from about 10-50 kyr depending on the spreading rate and water depth for the particular marine survey. The Cande \& Kent (1995) timescale, for example aims to have a uniform resolution in which all intervals longer than $30 \mathrm{kyr}$ are included. Short 
events may be unresolvable in this kind of record, as will excursions and any transitional states that may exist during reversals. Evidence for the existence of such features is provided by the cryptochrons, finer scale features documented by Cande \& Kent in the marine magnetic anomaly record back to $83 \mathrm{Ma}$. Some of these cryptochrons correspond to short events of stable magnetic polarity, while others may reflect changes in the paleointensity of the field. A distinction between these two causes cannot be made solely on the basis of the magnetic anomaly record: other paleomagneic data are required. The magnetic anomaly timescale only extends to about 160 Ma because of the scarcity of older seafloor.

An alternative method is used for finding the age of an individual reversal boundary for land-based paleomagnetic measurements and requires knowledge of the magnetic polarity and a radiometric date for a collection of different rock samples. In the Chronogram Technique (Cox \& Dalrymple, 1967) one finds the most probable age for individual reversal boundaries, by minimizing weighted squared deviations of a collection of $K / A r$ or $A r / A r$ ages for a range of test boundaries. Limitations of this method (Tauxe et al., 1992) are that one can only deal with data surrounding one reversal at time, the presumption that the polarity can be determined unambiguously, non-uniformity in the distribution of dates, and potentially inadequate estimates of the uncertainties in dating.

High resolution records of geomagnetic field behavior are now routinely recovered from marine sediments, and these can be dated using the so-called Astronomical Time Scale (ATS). ATS makes use of variations in Earth's orbital parameters (precession, obliquity, and eccentricity) for last few million years. The climatic response to these variations of ice sheet growth and decay can be approximately modelled. Then if there exists a high resolution record of Earth's response to this orbital forcing that can be tied into magnetostratigraphy this can be used to provide dates for reversals. Such a high resolution record was first provided in the form of fluctuations in the oxygen isotopes, $\delta^{18} O$. Johnson (1982) found a result from this method of 0.79Ma, which conflicted with the $0.73 \mathrm{Ma}$ age for the Brunhes-Matuyama boundary that was widely accepted at the time. This conflict was initially attributed to insufficiently high resolution records or uncertainties concerning the amount of time taken for magnetization to be locked into the continuously deposited sediment. In a later study Shackleton et al. (1990) used a detailed $\delta^{18} O$ record from Ocean Drilling Project Site 677 to place the Brunhes-Matuyama boundary at $0.78 \mathrm{Ma}$. A study from the Mediterannean by Hilgen (1991) on fluctuations in sapropels also associated with climate variations produced the same result. These results, combined with new radiometric measurements prompted a reexamination of the reliability of the $0.73 \mathrm{Ma}$ age derived from radiometric dating. Tauxe et al. (1992) showed using a simple bootstrap resampling scheme that the error bars on reversal times derived by the chronogram technique may be unrealistically small because of violations of assumptions made in the method, and thus that radiometric ages for the Brunhes-Matuyama boundary were not inconsistent with those derived via the ATS.

In the past decade the time at which the most recent reversals occurred has been estimated by direct ${ }^{40} \mathrm{Ar} /{ }^{39} \mathrm{Ar}$ dating of lava flows that record transitional paleomagnetic directions (e.g., Baksi et al. 1992; Singer \& Pringle 1996; Singer et al., 1999). The dating techniques now in use have a claimed precision of $0.5 \%$ on quaternary sanidine, or $0.5-1 \%$ on basaltic or andesitic lavas. These results confirm that the age of the most recent reversal is $0.78 \mathrm{Ma}$, and have spawned a new approach to calibrating the most recent part of the magnetostratigraphic time scale, and studying the structure of the geomagnetic field during reversals. This will be discussed in more detail in the section on duration of reversals.

\section{Reversal Rates}

\section{4:1 Measuring Rates}

The fundamental question that can be addressed using the information provide by the magnetostratigraphic time scale concerns the estimation of the frequency with which geomagnetic reversals recur. Since the earliest studies on this topic it has been apparent that the time elapsed between successive field transitions is highly variable. In the absence of a clear physical understanding of any fundamental mechanism and associated dynamics, reversals have been modeled in a phenomenological way. They have (following Cox, 1968) been regarded as uncorrelated, triggered events described by a Poisson process with a varying rate parameter. The rate parameter provides a statistical characterization for their times of occurrence, but it 


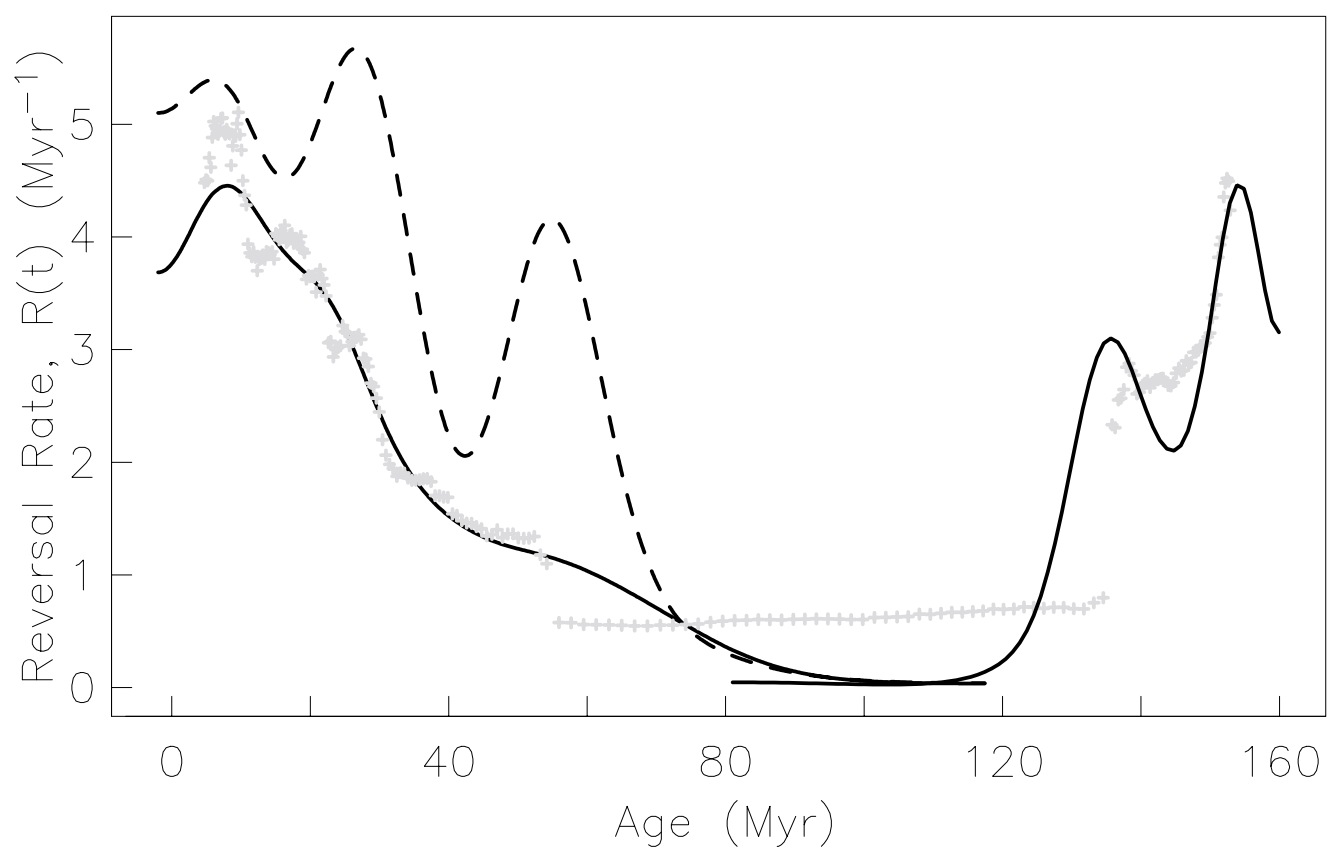

Figure 4: Reversal rates for past 160Ma derived by Constable (2000) using kernel density estimates. Dashed line is rate including cryptochrons, solid line without. Light gray symbols give rate for sliding window estimate.

should be kept in mind that there is no direct physical model that associates it with equations describing the physical evolution of the magnetic field in Earth's core. Figure 4 shows estimates of geomagnetic reversal rate as a function of time for the last $160 \mathrm{Myr}$ as determined by Constable (2000). The solid black line is based on adaptive Gaussian kernel estimates, in which each reversal is given unit weight, and the Cande and Kent (1995) timescale is used for 0-84 Ma, and Harland et al. (1990) prior to $84 \mathrm{Ma}$. Grey symbols are 50 point sliding window estimates, which cannot be considered independent, because of the overlap of adjacent windows. The dashed black line gives the kernel estimate when events identified by Cande $\&$ Kent as cryptochrons are treated as reversals. Whether these are very short polarity intervals, intensity fluctuations, or (perhaps more likely) some of both remains an open question. It is seen from this figure that there are long term changes in reversal rate: these have been variously attributed to gradual thermal changes in conditions at the core-mantle boundary (McFadden \& Merrill, 1984), the release of mantle plumes (Loper, 1992; Loper \& McCartney, 1986; Courtillot \& Besse, 1987; Larsen and Olson, 1991) or the sudden arrival of cold material at the CMB from a mantle flushing event (Gallet \& Hulot, 1997). A possibility that cannot be unequivocally ruled out, is that the apparent long term trend in reversal rates is simply what can be expected from a chaotic process producing the magnetic field in Earth's core.

The degree to which finer scale structure in the reversal rate curve should be interpreted as reflecting changes in the geodynamo has been hotly debated. Aside from the obvious limitations of such a statistical description, difficulties in estimating the rate parameter from small numbers of events mean that short term fluctuations in the rate cannot be reliably estimated. McFadden \& Merrill (1984) considered the reversal rate, $\lambda(t)$, to be varying in a piecewise linear fashion with time, with zero rate during the CNS. Rather than assuming a specific functional form for the temporal variation, Constable (2000) used a technique proposed by Hengartner \& Stark (1992a,b;1995) to compute pointwise confidence bounds on the temporal probability density function for geomagnetic reversals. The method allows the computation of a lower bound on the number of modes required by the observations, thus enabling a test of whether "bumps" are required features of the reversal rate function. Conservative $95 \%$ confidence intervals can then be calculated for the temporal location of a single mode or antimode of the probability density function. Using observations from the time interval 0-158 Ma it is found that the derivative of the rate function must have changed sign at least once. The timing of this 
sign change is constrained to be between 152.56 and $22.46 \mathrm{Ma}$ at the $95 \%$ confidence level. Confidence bounds are shown in Figure 5 for the reversal rate under the assumption that the observed reversals are a realization of an inhomogenous Poisson or other renewal process with an arbitrary monotonically increasing rate function from the end of the Cretaceous Normal Superchron (CNS) to the present, a zero rate during the CNS, and a monotonically decreasing rate function from M29R at 158 Ma to the onset of the CNS. The confidence limits on estimating the rate parameter are broad in comparison to the size of the shorter term fluctuations in rate. It is unnecessary to invoke more than one sign change in the derivative of the rate function to fit the observations.

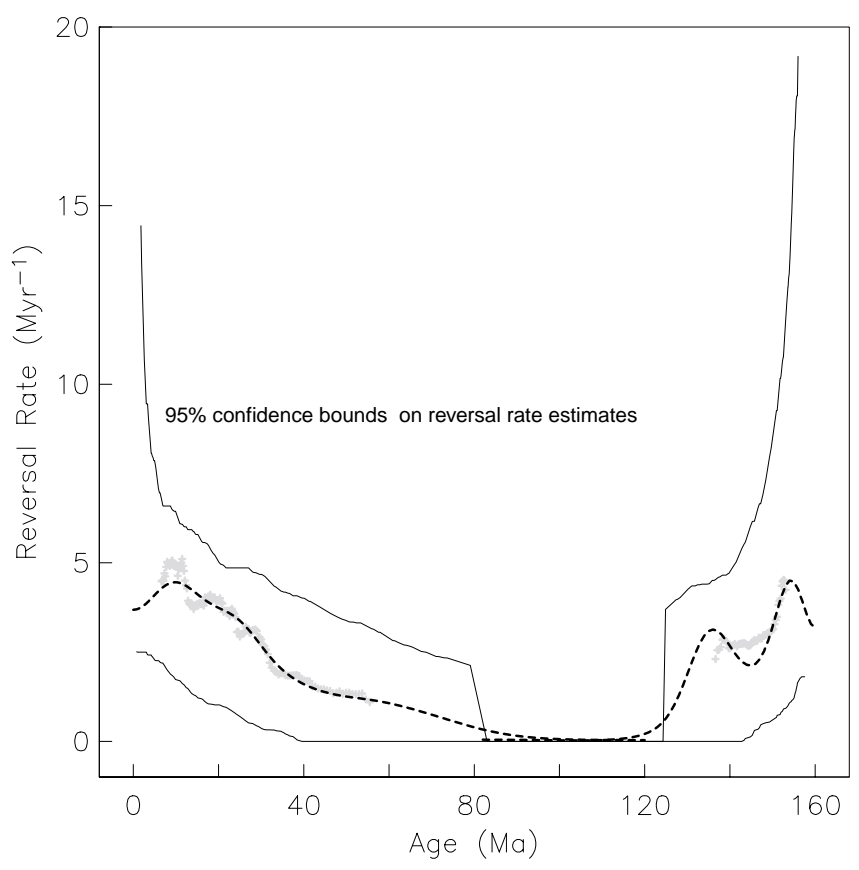

Figure 5: Reversal rates, excluding cryptochrons as in Figure 4, dashed line is kernel estimate, symbols sliding window rate, and solid lines are $95 \%$ confidence bounds on reversal rate under assumption that reversals are produced by a poisson process with monotonically decreasing rate parameter from 160-124 Ma, zero rate during the CNS, and montonically increasing from 83 Ma to present.

There is no incompatibility between these results and a recent assertion that there is an asymmetry in average reversal rate prior to and after the CNS (McFadden \& Merrill (1997)), when the CNS is assumed to be a period of zero reversal rate. Neither can the Poisson model be used to reject an alternative hypothesis that rates are essentially constant from 158 to $130 \mathrm{Ma}$, and from $25 \mathrm{Ma}$ to the present, with an intermediate non-stationary segment as envisaged by Gallet \& Hulot (1997).

\section{4:2 Reversal Rates and other Properties of the Geomagnetic Field}

The rate parameter alone is unlikely to provide an understanding of what controls changes in reversal rate, and we must turn to other kinds of paleomagnetic observations and numerical simulations to provide a guide in determining how rapidly it is possible for the rate to change, and what controls such changes. To date no long term correlation has been found between average absolute intensity of the paleomagnetic field and long term reversal rate (Selkin and Tauxe, 2000), although one was suspected for some time (see Prévot et al., 1990). It should be emphasized, however, that there remain insufficient data to characterize absolute paleointensity very well over the past $300 \mathrm{Ma}$, and in the CNS a period which is of great interest because of the absence of documented reversals there is only a handful of reliable absolute paleointensity data available despite continuing efforts to acquire such observations (see e.g. Tarduno et al., 2001). The difficulty in acquiring reliable data is in large part due to the scarcity of suitable geological formations with lava flows in the right age interval. 
The general paucity of absolute intensity data is to some extent mitigated by the increasing number of paleomagnetic records being acquired from marine sediments. These can provide long almost continuous records of both relative paleointensity and directional variations, although it is often the case that only one or the other is acquired. Such records are highly variable in both duration and resolution, but in the context of reversal rates it is worth noting that there are now at least 3 records of relative geomagnetic intensity available each spanning 4 million or more years of field variation at a single location (Valet \& Meynadier, 1993; Constable et al., 1998; Cronin et al., 2001).

Constable et al. (1998) did find in their analysis of an 11 million year long record from a single site (ODP 522 , with paleolatitude $33^{\circ} \mathrm{S}$ ) during the Oligocene that there was a weak correlation between relative paleointensity and polarity interval length. They also found differences in the power spectra of the intensity record. In the time interval 23-28 Ma, where the reversal rate is $4 \mathrm{Myr}^{-1}$, the spectrum of intensity variations is dominated by the reversal process in the frequency range 1-50 $\mathrm{Myr}^{-1}$. In contrast between $34.7 \mathrm{Ma}$ and 29.4 Ma, when the rate is about $1.6 \mathrm{Myr}^{-1}$, the field is stronger, more variable, and a strong peak occurs in the spectrum at about $8 \mathrm{Myr}^{-1}$ (see Figure 6). Constable et al. (1998) speculate that this peak is associated with the cryptochrons found in this time interval, although the time resolution in the record is not adequate to provide a definitive correlation with the magnetic anomaly record.

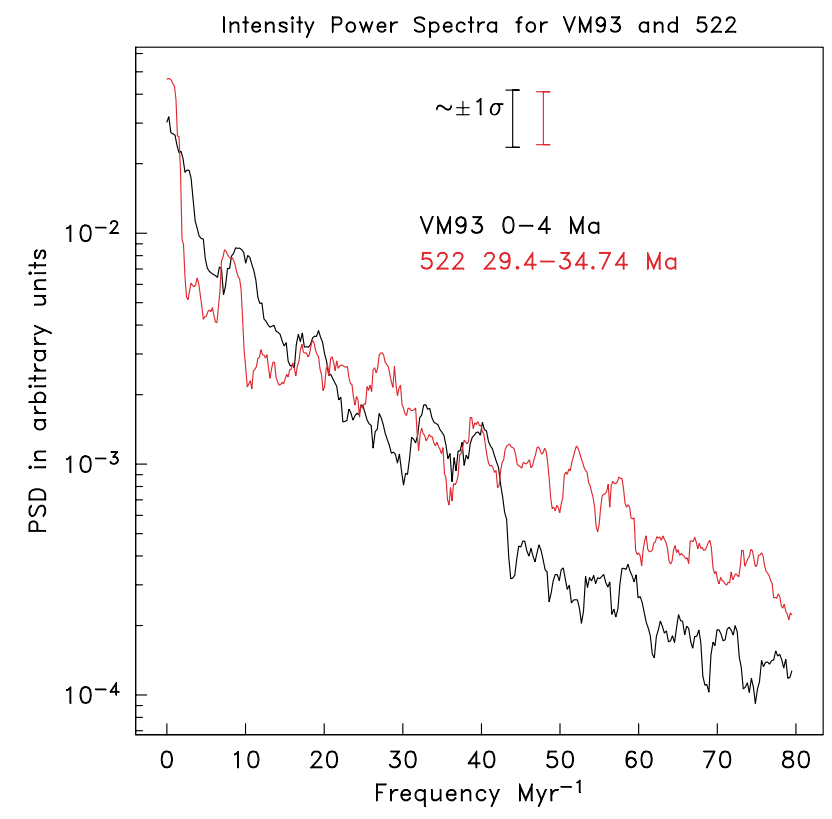

Figure 6: Power spectra derived from relative geomagnetic paleointensity records for 0-4 Ma (Valet \& Meynadier,1993), and low reversal rate time intervals during the Oligocene (Constable et al., 1998).

Analysis of Valet \& Meynadier's (1993) 0-4 Ma paleointensity record from ODP Sites 848, 851, and 852 in the equatorial Pacific reveals a spectral structure that is similar to that from ODP 522 in being dominated by power at low frequencies. When the errors in spectral estimation are taken into account it is unlikely that the spectra can be considered significantly different. However, the rapid drop in power between 0 and $5 \mathrm{Myr}^{-1}$ is distributed to slightly higher frequency in the more recent record, reflecting the influence of the sawtooth signal noted by those authors. The overall power in relative intensity variations is quite similar.

In a paleosecular variation study using Cretaceous age marine sediments collected in the Umbria-Marche region of Italy, Cronin et al. (2001) derived detailed relative paleointensity and direction records for a 4 Myr segment of the CNS extending from about 90-94 Ma, and find no convincing evidence for excursions. The Umbrian relative paleointensity record indicates a subdued variation in paleointensity during the CNS when 
paleointensity is normalized relative to the mean within each record. During the Oligocene when the field reverses, the standard deviation in intensity is about $50 \%$ of the mean value (for both low and high reversal rate periods), as it is during the past few million years (Valet \& Meynadier, 1993), while for the CNS data it is reduced to about $28 \%$ of the mean. The normalized intensity data distributions are clearly different, a fact that we may attribute to the difference in reversal rates between the two time intervals.

One might also expect greater directional stability for the magnetic field during times of low reversal rate. McFadden et al. (1991) show that the dispersion in VGP directions derived from globally distributed lava flows in the time interval 80-110 $\mathrm{Ma}$ is lower than during 0-5 Ma and have argued that the contribution of symmetric family spherical harmonics to VGP dispersion is decreased during the Cretaceous Normal Superchron (CNS). Cronin et al. (2001) find a very similar level of directional stability to that found by McFadden et al. for the time period 80-110 Ma for lava flows, despite the large differences in the nature of the two data sets: the lava flows are globally distributed spot readings of the field distributed over a $30 \mathrm{Myr}$ long interval which includes the transition to a period when reversals begin to occur again; in contrast each sediment datum from the $\sim 4 \mathrm{Myr}$ interval provides an average over about 3000 years at a single site whose paleolatitude is inferred to be $21^{\circ}$. There are also large differences in the size of the two data sets: Cronin $e t$ al. acquired over 800 measurements of direction and intensity; the lava flows provide a few hundred estimates of direction globally, but only 18 within the same latitude band $\left(10-25^{\circ}\right)$, although they are individually considerably better determined than the sedimentary observations. Nevertheless, the combined evidence from these two kinds of observations point to decreased variance in $\hat{v}$ during the CNS. Unfortunately no directional data exist for the Oligocene record which would allow such a comparison between reversals occurring at low and relatively high rates for that portion of the time scale.

\section{4:3 Longer Term Rate Variations, Numerical Dynamo Simulations, and Boundary Conditions}

The above discussion of reversal rate data has been limited to the time interval covered by the marine magnetic anomaly record for which a more or less complete record of geomagnetic reversals is available. There is evidence for large rate changes further back in time, and for at least one additional long interval of very low reversal rate the Permo-Carboniferous reversed Superchron (PCRS) from about 302-252 Ma. Johnson et al. (1995) have used indirect statistical arguments, with a method proposed by McElhinny (1971) and selected observations from the Global Paleomagnetic Database (Lock and McElhinny, 1991; McElhinny and Lock, 1993) to construct a model of relative reversal rate based on the fraction of mixed polarity results in moving windows of length $20 \mathrm{Myr}$ for the past $570 \mathrm{Myr}$. Their analysis suggested the possibility of a further time interval around $500 \mathrm{Myr}$ ago when the reversal rate was much reduced, and the polarity predominantly reversed. Magnetostratigraphic work by Pavlov \& Gallet (2001) confirms that a period with few or no reversals exists during the Ordovician, although its exact extent and the rates in surrounding intervals are not yet completely defined. The approximate time interval of around 150-200 Ma between successive superchrons is often equated with typical timescales for the overturn of the mantle, and thus linked to changes in core-mantle boundary conditions.

Investigations of both kinematic dynamos and full scale numerical simulations have been used to demonstrate the potential importance of boundary conditions in controlling geomagnetic reversals. Hollerbach and Jones (1993a,b; 1995) demonstrated that a finitely conducting inner core played a critical role in stabilising the magnetic field between reversals. It is thus plausible to suppose that growth of the inner core may in the past have had significant influence on the average structure of the geomagnetic field and dynamics in the outer core. Kent and Smethurst (1998) have suggested that pre-Mesozoic (older than $250 \mathrm{Ma}$ ) paleomagnetic data can be interpreted as offering some suppport for this kind of scenario: the abundance of shallow inclinations are compatible with substantially larger octupole contributions ( $\sim 25 \%$ of the axial dipole) to the field than seen in more recent times. However, note Tauxe's (1999) caution that such pre-Mesozoic data may be biased by noise contributed from inadequate knowledge of paleohorizontal. Kent and Smethurst attribute the additional field complexity to a smaller size for the inner core at that time, although Bloxham (2000b) found that in his numerical dynamo simulations reasonable variations in the size of the inner core (for the relevant time interval) had no detectable influence in increasing the complexity of the average field. While it is conceivable that the size and geometry of the outer core influence the propensity of the geomagnetic field to reverse, this seems unlikely to be a major contributor to the variations in reversal rate in the Cenozoic, because at this point in Earth's history the inner core is presumably only growing very slowly. 
Temporally changing and laterally varying core-mantle boundary conditions are viable candidates for changes in the field structure and reversal rate. The influence of various distributions of heat flux at the CMB have been explored in numerical simulations (Glatzmaier et al., 1999; Coe et al., 2000; Bloxham, 1998, 2000a,b; see Dormy et al., 2000 for a review). Bloxham concludes that $Y_{2}^{0}$ thermal structure can contribute to non-axial-dipole field structure, while Glatzmaier et al. infer that the propensity for the field to reverse is greatly enhanced by particular kinds of boundary conditions, such as the one that mimics the current thermal structure near the CMB. Quite different zonal thermal structures appear to be associated with simulations that do not exhibit reversals. It is difficult to envisage being able to run the current full 3-d numerical dynamos for long enough to generate adequate numbers of reversals to acquire statistically meaningful estimates of rate for a variety of boundary conditions, however, one can readily evaluate whether the spectrum of intensity variations (for example) is different, and explore whether it is possible to identify differences in the dynamical processes in the core associated with the different boundary conditions. It may be possible to make progress in understanding dynamical regimes that favor reversals, or why in some parts of the time scale cryptochrons appear quite common, while in others they are apparently absent. McMillan et al. (2001) have developed statistical tools for studying the output of numerical dynamo simulations and comparing them to properties of the paleomagnetic field. These have been applied to some of the Glatzmaier-Roberts numerical experiments with different boundary conditions, and clearly demonstrate more power in the secular variations for some scenarios than others.

An outstanding question, which has perhaps been obscured by the repeated analysis of paleomagnetic observations in terms of the Poisson process is how the geomagnetic field evolves from a state in which geomagnetic reversals occur to one without (or vice versa). Rapid changes in the rate parameter of a stochastic renewal process cannot be estimated accurately: yet it seems that the geomagnetic field readily evolved from a time when no reversals occurred (CNS) to one of quite frequent reversals over a time interval of some tens of millions of years. Such a timescale is significantly shorter than that generally attributed to changes at the $\mathrm{CMB}$ due to overturn of the mantle, so that one either has to invoke gradual changes that eventually pass some critical point allowing the initiation of reversal (as envisaged by e.g., McFadden \& Merrill, 2000), or alternatively one needs to investigate scenarios that involve mantle plumes or other processes in which significant changes in $\mathrm{CMB}$ conditions can be generated relatively rapidly.

\section{Structure and Duration of Reversals}

We turn now to the details of geomagnetic reversals, as opposed to the rate at which they occur. Once again there needs to be a critical emphasis on dating of paleomagnetic records, because this determines our ability to study such issues as how long the field spends in transition at any given site during any particular reversal. It is already obvious from Figure 1 that the duration of a reversal is likely to depend on geographic location if we use any of the standard measures to define a reversal, such as local VGP direction deviating from the geographic axis by more than a specified amount or decrease in paleointensity (DIP) to less than some critical percentage of the average. Note that this requires a clear concept of what the average is, something that is in general far from obvious.

\section{5:1 Observational Estimates of Duration:}

There are four potential sources of observational estimates for the duration of reversals, each related to the nature of the geological features preserving the record. We first consider the direct estimates. In marine sediments the sediment accummulation rate (SAR) can be used to find the age at which the transition begins and is completed (as defined by some specified directional deviation or DIP). This suffers from a number of disadvantages: the interval length is subject to fluctuations in SAR, to whatever interpolation used, and to smoothing or offsets in timing due to the lock in depth and filtering process (which may themselves depend on SAR) in the acquisition of remanence. These limitations are offset by the significant advantage that direct correlation to the ATS is possible in many cases using fluctuations in $\delta^{18} O$. The length of reversals found by this technique range from as short as 100 years (Worm, 1997) to more than $20 \mathrm{kyr}$ (Herrero-Bervera, 1987): it is very difficult to sort out the roles of the various individual factors that contribute to the large range, but in general shorter estimates are found when only directional information is considered than when preliminary decreases in paleointensity are taken into account. In a study of 8 Pacific marine cores Clement and Kent (1984) found indications that reversals took about twice as long at mid-latitudes as at low latitudes, 
but Valet et al. (1989) found no such relationship for 4 Atlantic cores from the latitude range $0-50^{\circ} \mathrm{N}$. More recently in a detailed study of sedimentary records of the Matuyama- Brunhes reversal Tauxe et al. (1996) found tantalizing suggestions that the age at which it occurred depended on geographic location, but were unable to rule out the possibility of variations in the timing at which the magnetic remanence is ultimately locked in.

The other direct approach uses radiometric dating on transitional lava flows from different locations, preferably potassium-rich sanidine bearing rhyolites. This has to date meant that the reversal is defined in terms of directional rather than intensity anomalies. As noted earlier the claimed precision on ${ }^{40} \mathrm{Ar} /{ }^{39} \mathrm{Ar}$ dating may be as good as $0.5 \%$ : for the Brunhes this means relative uncertainities at different sites of a few thousand years. The differences among ages of 8 transitional lava flows drawn from globally distributed locations (Chile, La Palma, Tahiti, and Maui) range up to $12 \mathrm{kyr}$, placing this as a plausible upper bound on the duration of directional variations for the last reversal (Singer and Pringle, 1996). This is a global estimate for the duration of the reversal: it should be kept in mind that at any given location the transition might appear to be initiated at a later or earlier time and have occurred considerably more (or perhaps even less) rapidly.

The number of transitions that are dated directly in multiple locations is very small indeed. An indirect statistical approach that does not necessarily require precise radiometric dates on lava flows takes the ratio of the number of transitional to non-transitional directions in some time window, and supposes that this indicates the amount of time the field spends in transition. Such a method is inevitably complicated by excursions, although if one takes the view that they are part of the same process as reversals this may not matter. Nevertheless, it is worth noting that direct radiometric dating by Singer et al. (1999) finds at least 7 and perhaps as many as 11 excursional directions, that could be interpreted as reversals attempts, in the time interval 1.18-0.78 Ma. Iceland is the archetypical location for duration estimates by such a statistical analysis as there are hundreds of flows that span several million years. Since the eruption of these flows can safely be regarded as uncorrelated with geomagnetic field behavior this can be presumed to provide an unbiased estimate of the time the field spends in whatever one defines as transitional directions. The value so obtained for Iceland is $6 \mathrm{kyr}$.

Durations have also been estimated indirectly from the cooling rates of intrusives rocks. This method has only rarely been used and requires assumptions about the cooling process that are hard to verify, therefore we will not consider it further here. Of the above the first two provide the most direct estimates, but all may be potentially complicated by precursory excursions extending the length of reversal. It is also possible that any such excursional features may themselves be inextricably bound up with variations in field intensity.

The vast range of times estimated for various reversals at different times and places indicate the inadequacy of the current dataset to resolve such issues as how long an individual reversal takes, whether the time taken varies with location, and/or with different reversals, and also whether it varies along with reversal rate. Although dating techniques are steadily improving, it seems unlikely that it will be possible to know ages to an accuracy much better than a few thousand years. Thus the possibility of directly modeling the structure of the geomagnetic field during a reversal remains remote (although this has not stopped people from trying, Mazaud, 1995; Shao et al., 1999). There are no such dating limitations in the records of geomagnetic reversals provided by numerical geodynamo simulations. A detailed analysis of the geomagnetic reversals found in the Glatzmaier-Roberts dynamo (Coe et al., 2000) indicates that reversal times vary widely depending on criteria used to determine onset of the reversal, but also with location, for successive reversals, and may exhibit different behavior depending on the thermal boundary conditions.

\section{5:2 Persistent Patterns?}

Despite the poor prospect for recovering details of the geomagnetic field structure during geomagnetic reversals, there have been longstanding efforts to characterize general properties associated with geomagnetic reversals. There are a number of fairly recent reviews on the subject of reversals, which discuss in some detail the magnetization of rocks and attempts to categorize the morphology of geomagnetic reversals (see for example Jacobs, 1994; Merrill and McFadden, 1999). These morphological descriptions are generally known as phenomenological models, and have evolved from those proposed by Creer and Ispir (1970) in which the dipole part of the magnetic field either decayed away and subsequently rebuilt in the opposite 
direction or rotated without variation in dipole moment.

Observations that are universally agreed upon for geomagnetic field transitions are, firstly, that they are incompatible with a zonal magnetic field structure during reversals: if such a field were present then the VGP positions at all sites would follow a path along either the site longitude or its antipode: that this is not so has been apparent since work by Hillhouse and Cox (1976). The second feature common to all transition records is a significant decrease in field intensity: this appears to be a necessary but not sufficient condition, since records of paleointensity for the Brunhes (e.g., Guyodo \& Valet, 1999) show many such decreases to about $20 \%$ of the average value: although a number of these may coincide with directional anomalies or excursions only the B-M boundary actually has a full geomagnetic reversal.

On the subject of more detailed, persistent structure in the magnetic field during reversals, there has been considerable controversy regarding interpretation of the available data. Valet \& Laj (1984) noted that 3 out of 4 reversals from Crete had longitudinally confined VGP paths, suggesting recurring behavior during successive reversals for a single site. Clement (1991) analysed VGP positions for the Matuyama-Brunhes transitions from globally distributed sites and noted preferential longitudes for VGP paths in the available records: he suggested that there was a simple field structure during this reversal. Laj et al. (1991) asserted that the simple structure had persisted for many reversals. Both of these assertions were criticized on the grounds that the global distribution of data was inadequate, and the possibility that biases in acquisition of magnetization by marine sediments, and /or statistical biases arising from possible distributions of directions would tend to favor reversal paths lying $90^{\circ}$ from the sites longitude, as was observed in a number of cases (e.g., Langereis et al., 1992: Egbert, 1992; Valet et al., 1992, plus many more). Constable (1992) noted that the preferred longitude bands were roughly aligned with one of those followed by globally distributed VGPs when the axial dipole part of the present field decays to zero amplitude before regrowing with the opposite polarity. Figure 1 (b) shows the probability density function for VGPs at the midpoint of such a process when there is no axial dipole present. The coincidence between preferred paths and the present field could be interpreted as due to a permanently preferred field structure like that of the present day field or residual overprinting of paleomagnetic records by the present field.

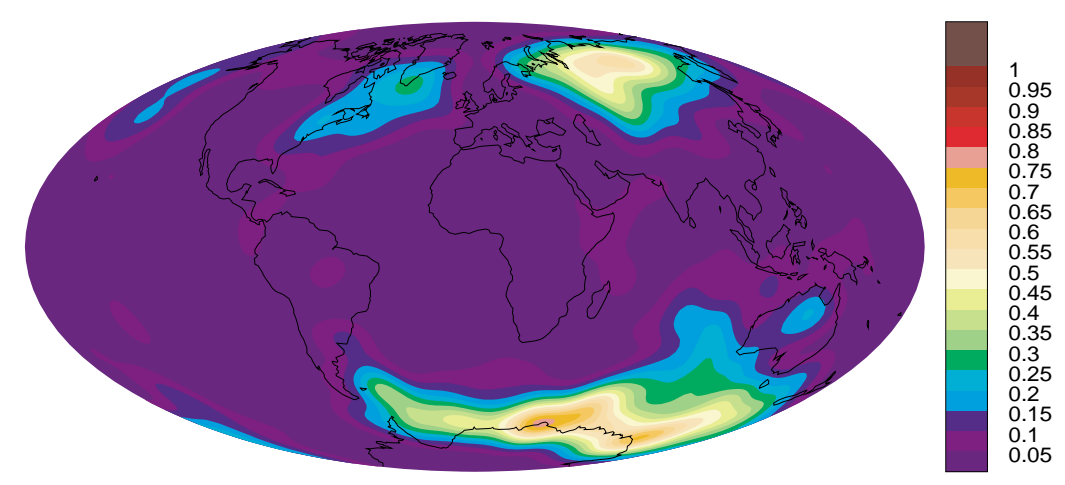

Figure 7: VGP density distribution for MBD97, the Matuyama-Brunhes transitional database compilation of Love \& Mazaud (1997) Each direction is assigned unit weight in estimating the density function.

The available reversal data have been reanalysed a number of times with conclusion in favor of or against the preferred paths. Recently 62 records of the Matuyama-Brunhes reversal were assessed by Love and Mazaud (1997), and winnowed to 11 in the MBD97 database. The remaining 11 still show preferred bands, even when weighted so that each site carries unit weight. Hoffman (2000) prefered to give each VGP direction (of which each record has a variable number) unit weight, and argues that when a running avergae of number of VGPs within circular caps is computed in this way, there is a preference for transitional VGP directions to lie in one of two preferred patches, north of Western Australia, and near the southern tip of America (see Figure 7, for the results from a similar calculation in which the density distribution for individual VGPs during the last reversal is calculated ). He interprets this preference as a sign that the geomagnetic field occupied an intermediate dipolar structure with a pole in one of these positions for a significant amount of time during 
the reversal, while other parts of the transition were executed quite rapidly. In the absence of sufficiently accurate age constraints on the individual flows concerned, it is difficult to test this assertion. The prefered paths for transitional fields have been associated with thermal structure at the core mantle boundary (Laj et al., 1991), as inferred from seismic tomographic models: difficulties with this interpretation remain in that it is not obvious what, if any, relationship should exist between the VGP positions and geomagnetic field structure and how either of these would be influenced by structure at the core-mantle boundary.

Love (1998) also reanalysed volcanic records of reversals and excursions for the past $20 \mathrm{Myr}$, and conclude that they too exhibit preferential paths in contradiction of a previous analysis by Prévot and Camps (1993). The major difference in the analysis was again in weighting, with regard to area dependence with latitude and number of intermediate directions for each record. The most significant contributors to the preferential longitudes were Icelandic records. Note the coincidence of this longitude with the VGP longitudes for Iceland for the present field seen in Figure 3. The question of why the present field should be of special significance during reversals is obscured somewhat by paleomagnetic evidence that the position of the dipole axis has been quite variable during the past few thousand years, and seems to show little preference for specific longitude bands (e.g., Constable et al., 2000).

The discussion of persistent patterns remains inconclusive, as with other features, however, we can turn to numerical gedynamo simulations in an attempt to guide our understanding. Glatzmaier et al. (1999) have run numerical simulations of the geodynamo using a variety of thermal boundary conditions, some of which appear to be more susceptible to reversal than others, although the time series are not sufficiently long to gather reliable statistics on the matter. In their analyses of the homogenous and tomographic versions of the model both Coe et al.(2000) and McMillan et al.(2001) found that all reversals appear spontaneous, with no external triggering required. The tomographic model was the least stable. Coe et al.observed that the time taken for individual reversals ranges from 2-7 kyr except for the second reversal in the tomographic model which takes $22 \mathrm{kyr}$ for the directional changes. The duration depends on the location, the reversal, and the criteria used to define transitional. All reversals were characterized by low intensities, and a sharp drop in dipole energy. The tomographic model of Glatzmaier et al. (1999) appears to offer some support for the hypothesis that VGPs during reversals correlate with areas of higher than average heat flux.

\section{Future Prospects in Geomagnetic Reversal Studies}

In concluding this review it seems relevant to consider what prospects there are for improved understanding of geomagnetic reversals in the foreseeable future. In the paleomagnetic arena, understanding of time scales is likely to see a steady improvement, with more detailed records of $\delta O^{18}$ in marine sediments and a better understanding of how magnetic remanence is acquired (see e.g., Katari \& Tauxe, 2000; Katari et al., 2000). Use of anisotropy of magnetic susceptibility and increasingly sophisticated tests for both physical disturbance and rock magnetic changes in sediments (e.g., Cronin et al., 2001) will allow better discrimination of which excursional records are reliable, as well as pinning down the timing of the multiple directional excursions that seem to occur in the late Matuyama and early Brunhes chrons. However, it remains unlikely that records with sufficient resolution and accuracy in dating will be acquired for a viable reconstruction of the geomagnetic field during a reversal.

On the other hand there are real possibilities for improving understanding of the relationship between geomagnetic reversal rate and other properties of the geomagnetic field. At present there are three fairly detailed records of relative geomagnetic paleointensity 4 Myr long or longer (from 0-4 Ma, Valet \& Meynadier, 1993, the Oligocene, 23-35 Ma and the CNS, approximately 90-94 Ma): it is possible to see the beginnings of associating reversal rates with particular kinds of geomagnetic field behavior. In the Oligocene low reversal rates correspond to higher average field intensity. Such high intensities seem to be associated with strong geomagentic field variations. During the Cretaceous we do not yet have a clear view of absolute paleointensity, but the field shows a remarkable degree of stability as measured by the variability relative to the mean. Additional absolute paleointensity measurements for the CNS are in the pipeline (Lisa Tauxe, 2001, personal communication; Tarduno et al., 2001). An increasingly detailed view of relative paleointensity variations is being acquired for the Brunhes (Guyodo \& Valet, 1999) with the advent of the SINT800 model, and numerical geodynamo simulations allow the investigation of the limitations of stacking of paleomagnetic records from diverse locations. It seems likely that this progress in data acquisition will allow us to move 
on from the primitive view of reversals as symptoms of a Poisson process at least to a statistical description with arbitrary temporal correlations.

\section{References}

Baksi, A.K., V.Hsu, M.O. McWilliams, \& E. Farrar, “ ${ }^{40} A r /{ }^{39} A r$ dating of the Brunhes-Matuyama geomagnetic reversal," Science, 256, 356-357 (1992).

Bloxham, J., "The effect of thermal core-mantle interactions on the palaeomagnetic secular variation," Phil. Trans. Roy. Soc. London, Series A, 358, 1171-1179 (2000a).

Bloxham, J., "Sensitivity of the geomagnetic axial dipole to thermal core-mantle interactions," Nature, 405, 63-65 (2000b).

Cande, S.C. \& D.V. Kent, "Ultrahigh resolution marine magnetic anomaly profiles: A record of continuous paleointensity variations," J. Geophys. Res., 97, 15,075-15,083 (1992).

Cande, S.C. \& D.V. Kent, "Revised calibration of the geomagnetic polarity timescale for the late Cretaceous and Cenozoic," J. Geophys. Res., 100, 6093-6095 (1995).

Chauvin, A., Duncan, R.A., Bonhommet, N., LeviI S., "Paleointensity of the Earth's magnetic field and K-AR dating of the Louchadière volcanic flow (Central France) - new evidence for the Laschamp excursion," Geophys. Res. Lett., 16, 1189-1192 (1989).

Clement, B.M., "Geographical distribution of transitional VGPs: Evidence for non zonal equatorial symmetry during the Matuyama- Brunhes geomagnetic reversal," Earth Planet. Sci. Lett., 104, 48-58 (1991).

Clement, BM., "Assessing the fidelity of palaeomagnetic records of geomagnetic reversal," Phil. Trans. Roy. Soc. London, Series A, 358, 1049-1064 (2000).

Clement, B.M., and Kent, D.V., "Latitudinal dependency of geomagnetic polarity transition," Nature, 310, 488 (1984).

Clement, B.M., Rodda P., Smith, E., Sierra, L., "Recurring transitional geomagnetic field geometries -evidenc from sediments and lavas," Geophys. Res. Lett., 22, 3171-3174 (1995).

Clement, B.M., and Stixrude, L., "Inner core anisotropy, anomalies in the time-averaged paleomagnetic field, and polarity transition paths," Earth Planet. Sci. Lett., 130, 75-85 (1995).

Coe, RS, Hongre, L, and Glatzmaier, GA, "An examination of simulated geomagnetic reversals from a palaeomagnetic perspective," Phil. Trans. Roy. Soc. London, Series A, 358, 1141-1170 (2000).

Constable, C.G., "Link between geomagnetic reversal paths and secular variation of the field over the past 5 Myr," Nature, 358, 230-232 ((1992)).

Constable, C., "On rates of occurrence of geomagnetic reversals," Phys. Earth Planet. Inter, 118, 181-193 (2000).

Constable, C.G., Johnson, C.L., and Lund, S.P., "Global geomagnetic field models for the past 3000 years: transient or permanent flux lobes?," Phil. Trans. Roy. Soc. London, Series A, 358, 991-1008 (2000).

Constable, C.G., Tauxe, L., Parker, R.L., “ Analysis of 11 Myr of geomagnetic intensity variation,” J. Geophys. Res., 103, 17735-17748 (1998).

Courtillot, V., \& J. Besse, “Magnetic field reversals, polar wander, and core-mantle coupling,” Science, 237, 1140-1147 (1987).

Cox, A., "Lengths of geomagnetic polarity intervals," J. Geophys. Res., 73, 3247 (1968).

Cox, A., \& B. Dalrymple, "Statistical analysis of geomagnetic reversal data and the precision of potassium-argon dating," J. Geophys. Res., 72, 2603-2614 (1967).

Cox, A., Doell, R.R., \& Dalrymple, G.B. , "Reversals of the Earth's magnetic field," Science, 44, 1537 (1964).

Creer, K.M., and Ispir, Y.,, " An interpretation of the behavior of the geomagnetic fiedl during polarity transitions," Phys. Earth Planet. Inter., 2, 283 (1970).

Cronin, M., L. Tauxe, C. Constable, P. Selkin, \& T. Pick, "Noise in the Quiet Zone," Earth Planet. Sci. Lett., 190, 13-30 (2001).

Dormy, E., Valet, J-P., and Courtillot, V., "Numerical models of the geodynamo and observational constraints," Geochemistry, Geophysics, Geosystems, 1, Paper No. 2000GC000062 (2000).

Egbert, G. D., "Sampling bias in VGP longitudes," Geophys. Res. Lett., 19, 2353-2356 (1992).

Gallet, Y., and Hulot, G., "Stationary and nonstationary behaviour within the geomagnetic polarity time scale," Geophys. Res. Lett., 24, 875-1878 (1997). 
Gee, J.S., S.C. Cande, J.A. Hildebrand, K. Donnelly, \& R.L. Parker, "Geomagnetic intensity variations over the past $780 \mathrm{kyr}$ obtained from near-seafloor magnetic anomalies," Nature, 408, 827-832 (2000).

Gilder, S., and Glen, J., "Magnetic properties of hexagonal coled-packed iron deduced from direct observations in a diamond anvil cell," Science, 279, 72-74 (1998).

Glatzmaier, GA, Coe, RS, Hongre, L, and Roberts, PH., "The role of the Earth's mantle in controlling the frequency of geomagnetic reversals," Nature, 401, 885-890 (1999).

Gubbins, D. , "The distinction between geomagnetic excursions and reversals," Geophys. J. Int., 137, F1-F3 (1999).

Guyodo, Y., \& Valet, J.P., "Global changes in geomagnetic intesnity during the past 800 thousand years,” Nature, 399, 249-252 (1999).

Harland, W.B., R.L. Armstrong, A.V. Cox, L.E. Craig, A.G. Smith, \& D.G. Smith, A geological time scale 1989. Cambridge University Press, Cambridge ( 1990).

Hengartner, N.W., \& P.B.Stark, "Confidence bounds on the probability density of aftershocks," University of California at Berkeley, Department of Statistics Technical Report, June 1992, \#352, 7pp (1992a).

Hengartner, N.W., \& P.B.Stark, "Conservative finite-sample confidence envelopes for monotone and unimodal densities," University of California at Berkeley, Department of Statistics Technical Report, September, 1992, \#341, 7pp (1992b).

Hengartner, N.W., \& P.B.Stark, "Finite-sample confidence envelopes for shape-restricted densities," The Annals of Statistics, 23, 525-550 (1995).

Herrero- Bervera, E., Theyer, F., and, Helsley, C.E., "Olduvai onset polarity transition: two detailed paleomagnetic records from North Central Pacific deep-sea sediments," Nature, 322, 159-162 (1987).

Hilgen, F.J. , "Astronomical calibration of Gauss to Matuyama sapropels in the Mediterranean and implications for the geomagnetic polarity time scale," Earth Planet. Sci. Lett., 104, 226-244 (1991).

Hillhouse, J. \& A. Cox, “Brunhes-Matuyama Polarity Transition,” Earth Planet. Sci. Lett., 29, 51-64 (1976).

Hoffman, K.A., "Temporal aspects of the last reversal of Earth's magnetic field," Phil. Trans. Roy. Soc. London, Series A, 358, 1181-1190 (2000).

Hollerbach, R, \& C. Jones, "A geodynamo model incorporating a finitely conducting inner core," Phys. Earth Planet. Inter, 75, 317-327 (1993a).

Hollerbach, R, \& C. Jones, "Influence of Earth's inner core on geomagnetic fluctutations and reversals," Nature, 365, $541-543$ (1993b).

Hollerbach, R, \& C. Jones, "On the magnetically stabilising role of the Earth's inner core," Phys. Earth Planet. Inter, 87, 171-181 (1995).

Jacobs, J.A., Reversals of the Earth's Magnetic Field. Cambridge University Press ( 1994).

Johnson, R.G., "Brunhes-Matuyama magnetic reversal dated at 790,000 yr BP by marine astronomical correlations," Quatern. Res., 17, 135 (1982).

Johnson, H.P., D. Van Patten, M.Tivey, \& W.Sager, "Geomagnetic polarity reversal rate for the Phanerozoic," Geophys. Res. Lett., 22, 231-234 (1995).

Katari, K., and Bloxham, J., "Effects of sediment aggregate size on DRM intensity: a new theory," Earth Planet. Sci. Lett., 186, 113-122 (2001).

Katari, K. and Tauxe, L., "Effects of $\mathrm{pH}$ and salinity on the intensity of magnetization in redeposited sediments," Earth Planet. Sci. Lett., 181, 489-496 (2000).

Katari, K, Tauxe, L. and King, J., "A reassessment of post-depositional remanent magnetism: preliminary experiments with natural sediments," Earth Planet. Sci. Lett., 183, 147-160 (2000).

Kent, D.V., \& J.C. Carlut, "Paleointensity record in zero-age submarine basaltic glasses: testing a new dating technique for recent MORBs," Earth Planet. Sci. Lett., 183, 389-401 (2000).

Kent, D.V., and Smethurst, M.A., "Shallow bias of paleomagnetic inclinations in the Paleozoic and Precambrian," Earth Planet. Sci. Lett., 160, 391-402 (1998).

Laj, C., A. Mazaud, R. Weeks, M. Fuller, \& E. Herrero-Bervera, "Geomagnetic reversal paths," Nature, 351, 447 (1991).

Langereis, C.G., A.A.M. van Hoof \& P. Rochette, "Longitudinal confinement of geomagnetic reversal paths as a possible sedimentary artefact," Nature, 358, 226-229 (1992).

Langereis, C.G., M.J.Dekkers, G.J. de Lange, M. Paterne, \& P.J.M. van Santvoort, "Magnetostratigraphy and astro- 
nomical calibration of the last 1.1Myr from an eastern Mediterranean piston core and dating of short events in the Brunhes," Geophys. J. Int., 129, 75-94 (1997).

Larson, R., \& P. Olson, "Mantle plumes control magnetic reversal frequency," Earth Planet. Sci. Lett., 107, 437-447 (1991).

Levi, S., Audunsson, H., Duncan, R.A., Kristjansson, L., Gillot, P.Y., Jakobsson, S.P., "Late Pleistocene geomagnetic excursion in Icelandic lavas - confirmation of the Laschamp excursion," Earth Planet. Sci. Lett., 96, 443-457 (1990).

Lock J., and McElhinny, M.W., " Special Issue - The global paleomagnetic database design, installation, and use with Oracle," Surv. Geophys., 12, 5-91 (1991).

Loper, D., "On the correlation between mantle plume flux and the frequency of reversals of the geomagnetic field," Geophys. Res. Lett., 19, 25-28 (1992).

Loper, D. \& K. McCartney, "Mantle plumes and the periodicity of magnetic field reversals," Geophys. Res. Lett., 13, $1525-1528$ (1986).

Love, J.J., "Paleomagnetic volcanic data and geometric regularity of reversals and excursions," J. Geophys. Res., 103, $12,435-12,452(1998)$.

Love, J.J., \& A. Mazaud, “A database for the Matuyama-Brunhes magnetic reversal,” Phys. Earth Planet. Inter., 103, 207-245 (1997).

Lund, S.P. et al., "Geomagnetic field excursions occurred often during the last million years," EOS, Trans. Am. geophys. Un., 79, 178-179 (1998).

Mazaud, A, "An attempt at reconstructing the geomagnetic field at the core-mantle boundary during the Upper Olduvai polarity transition (1.6 Myear)," Phys. Earth Planet. Inter., 90 , 211-219 (1995).

McElhinny, M.W., “Geomagnetic reversals during the Phanerozoic,” Science, 172, 157-159 (1971).

McElhinny, M.W., and Lock, J., "Global paleomagnetic database suppplement number one - update to 1992," Surv. Geophys., 14, 303-329 (1993).

McFadden, P.L. \& R.T. Merrill, "Lower mantle convection and geomagnetism,” J. Geophys. Res., 89, 3354-3362 (1984).

McFadden, P.L., and Merrill, R.T., "Asymmetry in the reversal rate before and after the Cretaceous Normal Polarity Superchron," Earth Planet. Sci. Lett., 149, 43-47 (1997).

McFadden, PL and Merrill, RT, "Evolution of the geomagnetic reversal rate since $160 \mathrm{Ma}$ : Is the process continuous?," J. Geophys. Res., 105, 28455-28460 ( 2000).

McFadden, PL, Merrill, RT, McElhinny, M.W., and Lee, S. , "Reversals of the Earth's magnetic field and temporal variations of the dynamo families," J. Geophys. Res., 96, 3923-3933 (1991).

McMillan, D.G., C.G. Constable, R.L.Parker \& G.A. Glatzmaier, "A statistical appraisal of magnetic fields of geodynamo models," G-cubed, in press (2001).

Merrill, R.T., M.W. McElhinny, \& P.L. McFadden, The Magnetic Field of the Earth: Paleomagnetism, the Core and The Deep Mantle. Academic Press, San Diego, California (1996).

Merrill, R.T., and McFadden, P.L., "Geomagnetic polarity transitions," Rev. Geophys., 37, 201-226 (1999).

Nowaczyk, NR., and Antonow, M., " High-resolution magnetostratigraphy of four sediment cores from the Greenland Sea .1. Identification of the Mono Lake excursion, Laschamp and Biwa I Jamaica geomagnetic polarity events," Geophys. J. Int., 131, 310-324 (1997).

Olsen, N., et al.(25 authors), “Ørsted initial field model,” Geophys. Res. Lett., 27, 3607-3610 (2000).

Pavlov, V. \& Gallet, Y., "Middle Cambrian high magnetic reversal frequency (Kulumbe River section, northwestern Siberia) and reversal behaviour during the Early Palaeozoic," Earth Planet. Sci. Lett., 185, 173-183 (2001).

Pouliquen, G., Gallet, Y., Patriat, P., Dyment, J., Tamura, C., "A geomagnetic record over the last 3.5 million years from deep-tow magnetic anomaly profiles across the Central Indian Ridge," J. Geophys. Res., 106, 10941-10960 (2001).

Prévot, M. \& P. Camps, "Absence of preferred longitude sectors for poles from volcanic records of geomagnetic reversals," Nature, 366, 53-56 (1993).

Prévot, M., M.E. Derder, M. McWilliams and J. Thompson, "Intensity of the Earth's magnetic field: evidence for a Mesozoic dipole low," Earth Planet. Sci. Lett., 97, 129-139 (1990).

Selkin, P., \& L. Tauxe, "Long term variations in geomagnetic field intensity," Phil. Trans. Roy. Soc. London, Series 
A, 358, 869-1223 (2000).

Shackleton, N.J., Berger, A., and Peltier, W.R., "An alternative astronomical calibration of the lower Pleistocene timescale based on ODP site 677," Trans. Roy. Soc. Edinburgh, Earth Sci., 81, 251-261 (1990).

Shao, JC, Fuller, M, Tanimoto, T, Dunn, JR, and others, "Spherical harmonic analyses of paleomagnetic data: The time-averaged geomagnetic field for the past $5 \mathrm{Myr}$ and the Brunhes-Matuyama reversal," J. Geophys. Res., 104, 5015-5030 (1999).

Singer, B.A., and Pringle, M.S., "Age and duration of the Matuyama-Brunhes geomagnetic polarity reversal from ${ }^{40} \mathrm{Ar} /{ }^{39} \mathrm{Ar}$ incremental heating analyses of lavas," Earth Planet. Sci. Lett., 139, 47-61 (1996).

Singer, B.A., K.A. Hoffman, A. Chauvin, R.S. Coe, and M.S.Pringle, "Dating transitionally magnetized lavas of the late Matuyama Chron: Toward a new ${ }^{40} \mathrm{Ar} /{ }^{39} \mathrm{Ar}$ timescale of reversals and events," J. Geophys. Res., 104, 679-693 (1999).

Tarduno, JA; Cottrell, RD; Smirnov, AV, "High geomagnetic intensity during the mid-Cretaceous from Thellier analyses of single plagioclase crystals," Science, 291, 1779-1783 (2001).

Tauxe, L., "How non-dipolar was the ancinet geomagnetic field?," EOS Transactions, American Geophysical Union, 80(46), F304 (1999).

Tauxe, L., A.D. Deino, A.K. Behrensmeyer and R. Potts, "Pinning down the Brunhes/Matuyama and upper Jaramillo boundaries: a reconciliation of orbital and isotopic time scales," Earth Planet. Sci. Lett., 109, 561-572 (1992).

Tauxe, L., T. Herbert, N.J. Shackleton and Y.S. Kok, "Astronomical calibration of the Matuyama-Brunhes boundary: Consequences for magnetic remanence acquisition in marine carbonates and the Asian loess sequences," Earth Planet. Sci. Lett., 140, 133-146 (1996).

Thouveny, N., and CREER, K.M., “ On the brevity of the Laschamp excursion,” Bulletin de la Societé géologique de France, 163, 771-780 (1992).

Valet, J-P., and Laj, C., "Invariant and changing transitional field configurations in a sequence of geomagnetic reversals ," Nature, 311, 352 (1984).

Valet, J-P., and Meynadier, L. , "Geomagnetic field intensity and reversals during the last four million years," Nature, 366, 234-238 (1993).

Valet, J-P., Tauxe, L., and B.M. Clement, "Equatorial and mid-latitude records of the last geomagenti reversal from the Atlantic Ocean," Earth Planet. Sci. Lett., 94, 371-384 (1989).

Valet, J.P., Tucholka, P., Courtillot, V., \& Meynadier, L., "Palaeomagnetic constraints on the geometry of the geomagnetic field during reversals," Nature, 356, 400-407 (1992).

Verosub, K., "Geomagnetic excursions and their paleomagnetic record," Rev. Geophys. Space Phys., 15, 145-155 (1977).

Vine, F. \& Matthews, D.H., “Magnetic anomalies over oceanic ridges,” Nature, 199, 947-9 (1963).

Vlag, P., Thouveny, N., Williamson, D., Rochette, P., Benatig, F., "Evidence for a geomagnetic field excursion recorded in the sediments of Lac St Front, Frnace - a link with the Laschamp excursion," J. Geophys. Res., 101, 28,21128,230 (1996).

Worm, Horst-Ulrich, "A link between geomagnetic reversals and events and glaciations," Earth Planet. Sci. Lett., 147, 55-67 (1997). 